\title{
ESTRATEGIAS DE ENSEÑANZA PARA EL DESARROLLO DE LA CREATIVIDAD EN LOS NIÑOS
}

\author{
Brunella Cereghino Cabrera
}

\begin{abstract}
RESUMEN
En este artículo se busca identificar y describir las bases comunes de aquellos procedimientos pedagógicos que estimulan la creatividad. Consideramos que formar personas creativas, que se adapten a contextos cambiantes, que sean capaces de obtener información a su alcance y aplicarla de modo diferente es una necesidad del presente siglo.
\end{abstract}

Educar niños creativos y capaces de resolver problemas por sí mismos no es tarea sencilla, requiere que los educadores busquen una metodología que permita llevar a cabo un proceso de enseñanza - aprendizaje que estimule la creatividad dentro de la asignatura que tiene a su cargo.

PALABRAS CLAVE

Educación, creatividad, estrategias de enseñanza, proceso creativo.

\section{ABSTRACT}

The present article searches to identify and describe the common bases of those pedagogical procedures that stimulate creativity. We believe that training creative people, who adapt to changing contexts that are able to get information at their fingertips and apply it differently is a necessity in this century.

Educating children who are creative and capable of solving problems by themselves is not an easy task, it requires educators to seek a methodology that allows them to carry out a teaching - learning process which stimulates creativity within the subject they are responsible for.

\section{KEYWORDS}

Education, creativity, teaching strategies, creative process.

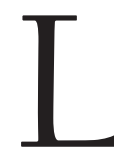

a creatividad es una característica inherente al ser humano, durante siglos la especie humana se ha servido de su habilidad para crear, para poder adaptarse, evolucionar y sobrevivir. En todo ser humano existe el impulso de experimentar, investigar, relacionar y en definitiva, de crear. Según Csikszentmihalyi (1995), todo ser humano posee un potencial creativo, susceptible de ser estimulado por el entorno familiar y social. Siguiendo la propuesta del autor, todas las personas poseen una configuración distinta de la creatividad y ésta puede expresarse de diferentes formas y grados; de manera general presentan un perfil de talentos, capacidades y motivaciones para una o varias áreas de desempeño. El entorno juega un papel importante en la estimulación, desarrollo y descubrimiento de estos talentos.

La niñez es un período crítico para la exploración del potencial creativo, es en esta etapa donde los niños libremente ponen a prueba sus habilidades y están deseosos de desarrollar más capacidades. Se encuentran en una etapa ideal para el desarrollo de su creatividad, aún no están atados a esquemas específicos para la resolución de problemas lo que les permite tantear diferentes vías para resolverlos. El aula de educación infantil es el escenario perfecto para mantener esa libertad, esa naturalidad con que los niños hacen frente a las dificultades que se le presentan, es el lugar idóneo para desarrollar lo que los autores Thomas y David Kelley (2013) llamaron confianza creativa.

Muchos países se encuentran poniendo en marcha reformas educativas que centran su atención en introducir mejoras de estructura, funcionamiento y normativas legales, otorgándole responsabilidad al 
docente para promover el desarrollo de las potencialidades físicas, intelectuales, morales y creativas de sus alumnos.

A nivel internacional, los países se encuentran sometiendo a revisión sus sistemas educativos a fin de alinearlos a las nuevas corrientes psicopedagógicas y demandas sociales.

Los nuevos escenarios que enmarcan la educación del siglo XXI, orientan a potenciar en sus alumnos las habilidades cognitivas superiores que les permitan lograr un trabajo autónomo y a desarrollar en ellos sus capacidades creativas y transformadoras que les ayuden a responder de forma eficaz a los cambios tecnológicos, sociales y culturales propios de esta era. En ese sentido, es importante plantearse la siguiente interrogante: ¿Qué estrategias de enseñanza fomentan el desarrollo de la capacidad creativa de los alumnos de educación infantil? Corresponde al educador organizar el ambiente educativo y proveer a sus alumnos experiencias enriquecedoras que permitan una educación innovadora y divergente acorde con las exigencias de la sociedad actual.

\section{Práctica educativa}

El docente no es un personaje neutral del sistema educativo, su práctica estará teñida de sus experiencias como alumno, maestro y ciudadano; de forma consciente o inconsciente, el maestro será permeable a una u otra metodología educativa. En la escuela se pueden encontrar profesores con los siguientes enfoques:

\section{a. Enfoquetradicional}

La principal noción de este enfoque es que el conocimiento es estático y transferible. Por lo general, el maestro explica de forma formal y académica lo que los alumnos tienen que aprender, para ello se apoya en material tradicional con el propósito de que los alumnos comprendan lo que se quiere decir; se toma en cuenta sólo la dimensión cognitiva del alumno. La escuela es considerada como una institución a la que los niños asisten para recibir la información que requerirán para poder integrarse en la sociedad en la que viven. El maestro vendría a ocupar el lugar del instrumento que transmite esa información que se encuentra en el mundo.

Si el alumno tiene que ir incorporando lo que se le enseña, la tarea del docente no es ni más ni menos que la de organizar las actividades del curso escolar en torno a una secuencia de temas o unidades didácticas que son reflejo de lo que el alumno debería saber en dicha etapa (Porlán 1998: 144).

Así, en el maestro recae la responsabilidad absoluta de lo que ocurre en el aula, es el encargado de elegir, organizar, marca el ritmo, secuenciar y distribuir los conocimientos que han de ser aprendidos a lo largo de todo el año escolar. Además, es un modelo y guía al que hay que seguir y obedecer, siendo sancionado el alumno que se desvíe de dicho enfoque.

Se valora la obediencia y el silencio como medio de atención. No hay lugar para compartir opiniones entre alumnos, entre los profesores y en menor medida entre profesor y alumno. Fuertemente centrada en la autoridad, este enfoque fomenta la competitividad como medio de motivación. En palabras de Piaget (1967), "en la escuela tradicional cada cual trabaja para sí (...), la clase no es más que la suma de individuos, no es una sociedad, la comunicación entre los niños está prohibida y la colaboración no existe apenas" (p. 34).

Como metodología educativa se tiende a inducir a los niños al pensamiento convergente y a la repetición. La pasividad con la que el alumno afronta su aprendizaje hace que las actividades terminen siendo automatizadas, lo que implica dejar de ver otras posibilidades o problemas que pueden afrontar.

\section{b. Enfoqueinnovador}

En este enfoque es fundamental el aprendizaje significativo y el respeto del estilo y ritmo de aprendizaje de los alumnos. Para la práctica del maestro es básico identificar los saberes previos de sus estudiantes, en ellos planifica las actividades a realizar. Estas actividades son lúdicas, se utiliza materiales concretos con finalidades didácticas. 
Asimismo, las clases y métodos de enseñanza ejercitan el pensamiento divergente, son dinámicas y sensibles a la realidad social de los alumnos. Éstos pueden expresar sus ideas, aportaciones e hipótesis. El profesor promueve el debate entre sus estudiantes y se nutre de las experiencias de sus colegas.

La disciplina no es autoritaria, ésta incluye acuerdos y ejercicio adecuado de la autoridad. Se le da prioridad al compañerismo y trabajo en equipo por encima de la competitividad entre compañeros.

Este segundo enfoque será el escenario ideal para poner en práctica los métodos de enseñanza que permitirán el desarrollo de la creatividad. A continuación se abordará ese tema.

\section{Enseñanza creativa}

Llevar la creatividad al aula de educación infantil la enriquece en muchos sentidos y permite producir nuevos conocimientos, instrumentos y procedimientos. Se puede anticipar el futuro e inventar soluciones nuevas a problemas reiterativos. Sin embargo, gestionar la creatividad en un salón de clase no es tarea fácil, el docente debe manejar las estrategias pertinentes para guiar a sus estudiantes en el proceso creativo y sobretodo debe creer que esa metodología es la adecuada para aprender. La preparación previa del docente es imprescindible, tiene que tener previsto qué materiales pueden ser útiles, debe aprender a observar el proceso y vigilar que el niño evolucione, debe conocer la materia que el alumno va a aprender. Asimismo, debe programar unos objetivos para que el proceso sea coherente, buscar varios instrumentos de evaluación, que le permita evaluar no solo desde un punto de vista cuantitativo sino también cualitativo.

Por otro lado, Menchén (1998) nos proporciona cuatro principios básicos que deberían estar presentes en toda programación de clase que busque fomentar la creatividad.

a. Principio de espontaneidad: el alumno debe exponer con libertad sus ideas, opiniones y experiencias. Esto le servirá para darle confianza y seguridad en sí mismo, así como podrá descubrir la importancia de comunicarse. Además, vivenciará la posibilidad de poner a prueba sus ideas y concepciones de la vida, creando en el aula un clima de respeto y apertura.

b. Principio de dialoguicidad: el diálogo permite al alumno conocer otras inquietudes y dar a conocer las suyas a través de éste. Al mismo tiempo da lugar a la contraposición de puntos de vista. No sólo se dará entre compañeros, sino también entre el alumno y el profesor.

c. Principio de originalidad: requiere buscar nuevas ideas e iniciativas que rompan con la cotidianidad. Busca desarrollar la flexibilidad mental del alumno, tanto hacia sus propias ideas como hacia la de sus compañeros.

d. Principio de criticismo: consiste en dudar de todas las certezas espontáneas para la construcción de su propio aprendizaje. Busca una actitud activa y crítica del alumno, junto con el profesor, deben analizar la información que obtienen y dudar de la misma con una actitud constructiva y crítica.

Los principios anteriormente presentados, "requieren que el alumno participe en el aula de forma activa y no pasiva y que las metas de esta etapa educativa sean: la libertad de acción, el saber escuchar, la participación, la tolerancia y la autonomía" (Menchén 1989: 318).

Ahora bien, una vez delineados los principios generales que se ubican en la base de toda programación de un aula creativa, ahora se señalará, siguiendo al mismo autor, algunas estrategias de enseñanza que estimulan la creatividad.

a. Estrategias generales: en este tipo de estrategias el lenguaje debe ir más allá de las convenciones aceptadas y de lo pertinente. Ejemplos de algunas técnicas son: el uso del humor, el juego de palabras, las analogías, la escritura creativa, la lectura creativa, las paradojas, las preguntas y repreguntas, y la visualización.

Las actividades lúdicas despiertan la motivación y ésta es básica para hacer algo 
creativo. Este tipo de actividades estimula la espontaneidad, la imaginación y la intuición en los alumnos.

b. Técnicas de sensibilización: consisten en proponer algo para ver qué sucede. El propósito de esta estimulación es incorporar ideas a la mente a fin de generar líneas de pensamiento nuevas y creativas. Algunas técnicas son el role playing, pensamiento inverso, lluvia de ideas, collage y resolución de problemas.

Asimismo, se debe considerar el aula de clase como un espacio abierto; por lo tanto, los materiales deben estar colocados de forma que los niños puedan acceder a ellos sin dificultad, se debe agrupar adecuadamente a los alumnos, debe haber variedad de materiales y correctamente distribuidos en el salón. Diversos estudios consultados, concluyen que crear un "ambiente flexible permite una mayor fluidez, flexibilidad y originalidad y mayor grado de elaboración en los trabajos de los niños" (Espriú 2005).

\section{CONCLUSIÓN}

Utilizar estrategias de estimulación creativa en el aula de educación infantil es necesario, pero si queremos desarrollar el pensamiento divergente en los niños, debemos buscar una enseñanza que favorezca la autonomía del niño, debemos crear un ambiente democrático en el aula que permita al niño dar sus opiniones y respetar a los demás.

Asimismo, se debe tener en cuenta la individualidad de cada uno de los alumnos y alumnas, permitiéndoles desarrollar sus propias capacidades y fomentando sus intereses personales.

\section{REFERENCIAS}

Cemades Ramírez, I. (2008). Desarrollo de la creatividad en educación infantil: Perspectiva constructivista. Revista Creatividady Sociedad, 2, 7-20.

Csikszentmihalyi, M. (1995). Creativity: Flow and the Psychology of Discovery and Invention. Nueva York, Estados Unidos: Harper Perennial.

Díaz Andrade, J. (2013). ¿Qué estrategias de enseñanza y aprendizaje fomentan el desarrollo de la capacidad creativa en estudiantes de preparatoria presencial en el aprendizaje efectivo en el área de ciencias sociales? Revista Iberoamericana para la Investigación y el Desarrollo Educativo, 6(3), 237-267.

Espriú, R. (2005). El niñoy la creatividad. México D. F., México: Editorial Trillas.
Kelley, T. y Kelley, D. (2013). Creative Confidence: Unleashing the creative potential within us all. San Francisco, Estados Unidos: Crown Pub Inc.

Menchén, F. (1998). Descubrir la creatividad: Desaprender para volver a aprender. Madrid, España: Pirámide.

Ruiz Gutiérrez, S. (2010). Práctica educativa y creatividad en educación infantil (Tesis doctoral). Málaga, España: Universidad de Málaga.

Vásquez Valdivia, J. (2011). La creatividad y la intervención en educación infantil. Recuperado de www.eduinnova.es/monografias2011 /ene2011/creatividad.pdf

Villegas Fernández, B. (2008). Estrategias docentes en el desarrollo de la creatividad escolar. REDHECS, 5 (3), 65-76. 